\title{
Economic and Social Aspects of Secondary Lymphedema following Treatment of Breast Cancer
}

K. Pitr (Karel Pitr)

SEU PhD. program and REHA-PITR s.r.o., Czech Republic.

\section{E-mail address:}

pitrk@volny.cz

\section{Reprint address:}

Karel Pitr

SEU PhD. program and REHA-PITR s.r.o.

Plaska 66a

Plzen

Czech Republic

Source: Clinical Social Work and Health Intervention

Pages: 35 - 38

\section{Reviewers:}

Juraj Benca

Clinic st. Maximiliana Kolbeho, House of family, Phnom Penh, Cambodia

P.Haj Ali

Erbil - Clinic bl. Zdenky Schellingovej, Irak

\section{Keywords:}

Breast Cancer. Economic Burden. Lymphedema. Qualitative Analysis.

\section{Publisher:}

International Society of Applied Preventive Medicine i-gap

CSWHI 2021; 12(2): 35 - 38; DOI: 10.22359/cswhi_12_2_06 CC Clinical Social Work and Health Intervention

\section{Abstract:}

\section{Introduction}

The quality of life of female patients who have undergone mentally and physically demanding treatment of cancer is often affected by the emergence of secondary lymphedema. The purpose of our work is to evaluate this complexity not only from an objective but also subjective point of view.

\section{Methods}

Qualitative focus study in 18 patients under 60 years of age conducted by way of a structured interview during 2019 at the lymphological workplace.

\section{Results}

The economic burden for patients is on the average CZK 683 per month (about $\$ 360$ USD per year), the treatment is paid for fully by health insurance companies. Lymphedema is a significant barrier in an occupation, more in women after treatment of the second grade of cancer than the first one. Lymphedema 
is a bigger obstacle for women with lower education, physically working. Family status does not have a significant effect on the treatment of cancer.

\section{Conclusions}

The study has confirmed the difficulty of treatment of secondary lymphedema after the treatment of breast cancer, both from financial and professional points of view. The medical staff should take into account these factors or expand the rehabilitation team and thus ensure better compliance in therapy.

\section{Introduction}

The secondary lymphedema is a common complication of breast cancer treatment. Its incidence increases in parallel with the increasing incidence of breast cancer and the improvement of the prognosis and thus the number of surviving patients. It is repeatedly demonstrated (1.2) that the quality of life of patients who have survived severely mentally and physically difficult treatment of cancer suffer from the development of subsequent lymphedema. The purpose of our work is to evaluate this complexity not only from an objective but also subjective point of view.

\section{Methods}

In view of the fact that our goal is to evaluate primarily the subjective burden of patients with secondary lymphedema and to understand the obstacles and facilitators for compliance, possibly adherence, we used a qualitative method of research. The study was conducted in 2019 in a department specialized in the rehabilitation of oncology patients. It included 18 women after treatment of breast cancer treated for secondary lymphedema after the first one. The conditions of acceptance to the study were following: Women had to be younger than 60 ; before the retirement age. So we evaluated a group of women aged from 27 to 56 years old, with an average age of 45.78 years, a median of 46 , a standard deviation of 8.07 .

As a method of qualitative research, a focus group was chosen and as a way of obtaining data was chosen a structured conversation which will allow to unify the data obtained from individuals and at the same time to evaluate the subjective perception of reality. This subjective perception of reality was converted into degrees of:

Subjective financial burden by treatment: 1 minimum 2 - medium 3 - high $\mathbf{4}$ - hard to manage Lymphedema as an obstacle in an occupation:
1 - not manifested $\mathbf{2}$ - mild 3 - severe 4-impossible to work

\section{Results}

Assessing family status: 10 women lived with family; 7 only with a partner; only lived alone. Family status did not affect the overall burden of lymphedema treatment, according to the opinion of the husbands. In relation to profession: 5 women worked physically, 1 was a housewife; 5 were permanently fully disabled; the other 7 worked mentally. All 5 women who were in full disability pension evaluated their lymphedema problems as serious, making it impossible to work because 2 of them originally worked as waitresses, 1 as a nurse and 2 as shop assistants.

The size of lymphedema was measured as the largest difference in circuits and was at least 5 and a maximum of $3 \mathrm{~cm}$, on average $1.5 \mathrm{~cm}$ (median 1.5, standard deviation 0.65). Lymphedema was rated as a barrier to work by more serious women after treatment for second grade cancer than the first one. Higher grades cannot be evaluated due to the low frequency.

Chart 1: seriousness of obstacle in occupation (1-4) in dependence on size of swelling

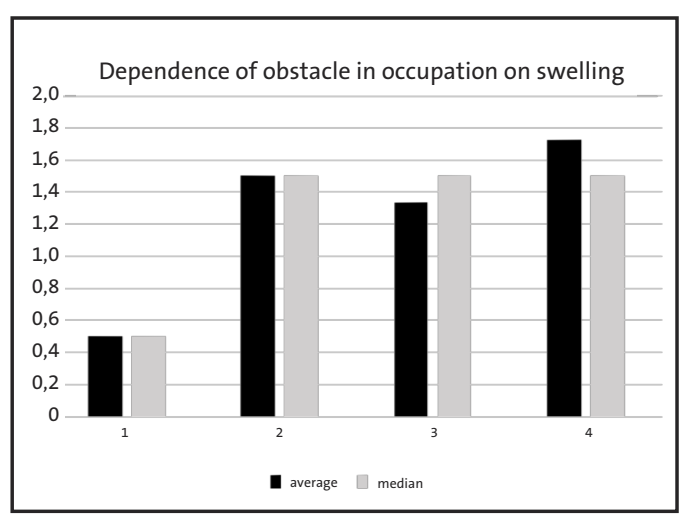


The average month cost of treatment for lymphedema in patients was CZK 683 (median 500, standard deviation 433). The treatment was covered by health insurance companies.

The financial difficulty of treatment with lymphedema objectively is slightly lower in women with second grade cancer than with the first one, but subjectively, the financial burden is perceived worse in the second grade than in the first one. Our patients showed a high quality of consumer credit, only two were credited, but not with high credit. The size of the swelling can be considered as an obstacle in occupation, as well as the lower the education, the greater the barrier in occupation.

\section{Chart 2: impact of education on seriousness of lymphedema as an obstacle in occupation}

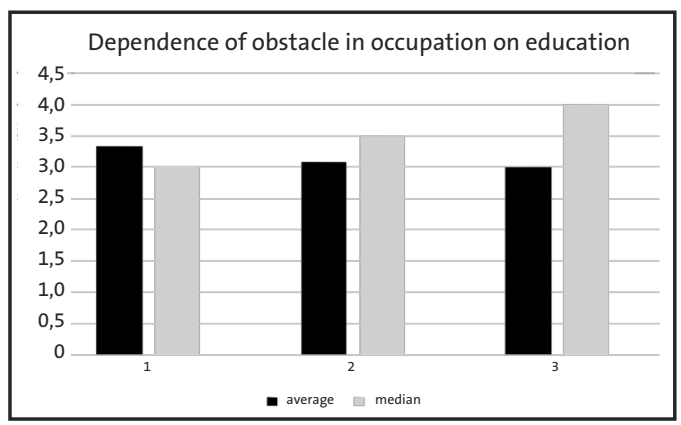

$1-$ primary + apprenticed

2 - secondary

3 - university

\section{Discussion}

In our study, according to the subjective observations of patients, family status does not have a significant effect on the overall burden of lymphedema treatment. According to other authors, this influence is significant (1) both in the field of occupation and in personal life (2). The reason is probably a different economic and cultural environment. The greater impact of lymphedema on women with lower education and therefore physically working our study shows a consensus (3).

The financial cost of treatment for our patients is significantly lower, i.e. $\$ 360$ per year compared to financial claims in the US, where it is $\$ 500$-\$1215 per year (4): Belgian authors report the cost of patient-bearing at $\$ 3,325$ to $\$ 5,545$, the cost of the company is $\$ 1,127$ to $\$ 3,165$ (5). According to the results of our study, lymphedema is usually a significant barrier to work, which is in conformity with most authors (1.6).

\section{Conclusions}

The study has confirmed the difficulty of treatment of secondary lymphedema after the treatment of breast cancer, both from the financial and professional points of view. The problem appears in patients with lower education which means working physically. The physicians, lymph therapists and physiotherapists should take into account these factors and cooperate with psychologists and social workers and provide better psychological and economic comfort for women treated for secondary lymphedema after treatment for breast cancer. In this way, better compliance and adherence in treatment can also be achieved, which is a necessary condition for its effectiveness.

The author was not supported by any company or sponsoring organization when creating the work, the work is not part of the grant. The author is not aware of a conflict of interest and has no direct or indirect interest in the production or sales results.

\section{References}

1. VIGNES S, FAU-PRUDHOMOT P, SIMON L, SANCHEZ- BRECHOT M L, ARRAULT M, LOCHER F (2020). Impact of breast cancer-related lymphedema on working women. Supportive Care in Cancer [online]., 28(1), 7985[cit. 2020-03-10]. DOI: 10.1007/s00520019-04804-2.ISSN 0941-4355. Available from:http://link.springer.com/10.1007/s00520019-04804-2.

2. BOING L, PEREIRA G S, DA CRUZ RAMOS DE ARAUJO C, SPERANDIO F F, DA SILVA GEVAERD LOCH M, BERGMANN A, BORGATTO A F, iana COUTINHO DE AZEVEDO GUIMARAES A (2019). Factors associated with depression symptoms in women after breast cancer. Revista de Saude Publica [online] 53 [cit. 202003-10]. DOI: 10.11606/S1518- 8787. 2019 053000786. ISSN 1518-8787. Available: https://www.revistas.usp.br/rsp/article/view/15 6159. 
3. PUGH S (2020) Importance of a collaborative approach to lymphoedema management. British Journal of Community Nursing [online]. 2019, 24 (Sup4), S30-S31 [cit. -03-10]. DOI: 10.12968/bjen.2019.24.Sup4.S30.ISSN 1462-4753. Available from: http://www.magonlinelibrary.com/doi/10.12968/bjen.2019.24 .Sup4.S30.

4. DEAN L T, MOSS S L, RANSOME Y, FRASSO-JARAMILLO L, ZHANG Y, VISVANATHAN $\mathrm{K}$, NICHOLAS $\mathrm{L} \mathrm{H}$, SCHMITZ K H (2020) It still affects our economic situation: long-term economic burden of breast cancer and lymphedema. Supportive Care in Cancer [online]. 2019, 27(5), 16971708 [cit. -03-09]. DOI: 10.1007/s00520-0184418-4. ISSN 0941-4355. Available from: http://link.springer.com/10.1007/s00520-0184418-4

5. DE VRIEZE,T, NEVELSTEEN I, THOMIS S, DE GROEF A, WIEBREN A. A.TJALMA, GEBRUERS N,DEVOOGDT N (2020) What are the economic burden and costs associated with the treatment of breast cancer-related lymphoedema? A systematic review. Supportive Care in Cancer [online]. 28(2), 439-449 [cit.2020-03-10]. DOI: 10.1007/s00520-01905101-8. ISSN 0941-4355. Available from: http://link.springer.com/10.1007/s00520-019 05101-8.

6. KALFA S, KOELMEYER L, TAKSA L, WINCH C, VIVEROS H, GOLLAN P J, MACKIE H, BOYAGES J (2018) Work experiences of Australian cancer survivors with lymphoedema: A qualitative study. Health \& Social Care in the Community [online].27(4), 848-855 [cit. 2020-03-10]. DOI: 10.1111/hsc. 12698. ISSN 0966-0410. Available from: https://onlinelibrary.wiley.com/doi/ abs/10. 1111/hsc.12698. 